\title{
Uma análise do contexto social, familiar e escolar em boku no hero (my hero academia): vai plus ultra!
}

\author{
An analysis of the social, family and school context in Boku no Hero (My \\ Hero Academy): Go plus ultra!
}

\author{
Masaaki Alves Funakura \\ Graduação em História \\ Universidade La Salle - Unilasalle \\ Canoas, RS - Brasil. \\ masaaki.funakura0342@unilasalle.edu.br \\ Fabiula Campos Falcão Fagundes \\ Mestra em Educação \\ Universidade La Salle - Unilasalle \\ Canoas, RS - Brasil \\ fabiulafalcaofag@gmail.com \\ Gelson Vanderlei Weschenfelder \\ Mestra em Educação \\ Universidade La Salle - Unilasalle \\ Canoas, RS - Brasil \\ gellfilo@gmail.com
}

Resumo: O intuito deste artigo é realizar uma análise diante ao anime Boku no Hero Academia (My Hero Academia) e descrever o contexto social, familiar e escolar, com ênfase no protagonista Izuku Midoriya e na relação entre professor e aluno, buscando compreender e alinhavar temas pertinentes ao contexto (escola, família e professor) do indivíduo e suas nuances capazes de somar na obtenção de compreensão da tríade que vem sendo objeto de estudos de diversos pesquisadores na esfera educacional. Sendo assim, há como centralidade as seguintes problemáticas: quais os elementos da sociedade apresentada na narrativa movem o personagem para obter suas virtudes? Quais possíveis papéis a escola pode desempenhar para a potencialidade do aluno que não está "inserido" na sociedade? O núcleo familiar poderá ser uma forma distinta para uma educação e formação do indivíduo? Para atender os objetivos, a pesquisa ocorreu de modo a conceituar como os autores estão refletindo diante os estudos referentes à cultura pop na educação, ou seja, é uma pesquisa qualitativa, em que tais documentos foram analisados por meio da Técnica de Análise de Conteúdo, proposta por Bardin (2011). Assim, obteve-se resultados satisfatórios ao permear assuntos extremamente pertinentes relacionados com a nossa vivência no âmbito escolar, destacando como o conjunto das entidades social, familiar e escolar se torna essencial para o desenvolvimento e para a constituição da personalidade do ser humano, em que os valores presentes nessa sociedade ficcional impulsionam os indivíduos, resultando ganhos ped agógicos. Por fim, personagens que representam o educador do colégio ficcional em questão, que, a partir de suas didáticas, propiciam aos alunos um espaço agradável e aberto para a troca de experiências, estratégias para a elevação da auto-estima e desenvolvimento de parâmetros para ampliar pensamento crítico e reflexivo, aspectos essenciais para a efetivação da relação professor-aluno e a aprendizagem.

Palavras chave: educação; mediação cultural; anime; escola; professor; aluno.

Abstract: The purpose of this article is to analyze the anime of Boku no Hero Academia (My Hero Academia) and describe the social, family and school context, with emphasis on the protagonist Izuku Midoriya and the relationship between teacher and student, seeking to understand and align relevant issues to the context of the individual, school, family and teacher, and their nuances that can add to the understanding between this triad that has been the subject of studies by several researchers in the educational sphere. Thus, having as centrality the following problem: what elements does the society presented in the narrative move the character to obtain his virtues? What possible roles can the school play for the potentiality of the student who is not "inserted" in society? Can the family nucleus be a different way for the education and formation of the individual? To meet the objectives, the research occurred in order to consider how the authors are considering the studies on pop culture in education, i.e., it is a qualitative research, such documents were analyzed using the Technique of Content Analysis, proposed by Bardin (2011). The results obtained were satisfactory, permeating extremely relevant issues that relate to our experience in the school environment, highlighting how this triad, social context, family and school, becomes essential for the development and constitution of the perso nality of the human being, that the values present in this fictional society drive individuals, resulting in pedagogical gains. Finally, the characters that represent the educator of the fictional school in question, who through his didactics provides the students with a pleasant and open space for the exchange of experiences, strategies for the elevation of self-esteem and developing parameters to expand critical and reflective thinking, essential aspects for the effectiveness of the teacher-student relationship and learning.

Key-words: education; cultural mediation; anime; school; teacher; student.

Cite como

\section{(ABNT NBR 6023:2018)}

FUNAKURA, Masaaki Alves; FAGUNDES, Fabiula Campos Falcão; WESCHENFELDER, Gelson Vanderlei. Uma análise do contexto social, familiar e escolar em boku no hero (my hero academia): vai plus ultra! Dialogia, São Paulo, n. 39, p. 1-19, e20022, set./dez. 2021. Disponível em: https://doi.org/10.5585/39.2021.20022.

\section{American Psychological Association (APA)}

Funakura, M. A., Fagundes, F. C. F., \& Weschenfelder, G. V. (2021, set./dez.) Uma análise do contexto social, familiar e escolar em boku no hero (my hero academia): vai plus ultra! Dialogia, São Paulo, 39, p. 1-19, e20022. https://doi.org/10.5585/39.2021.20022. 


\section{Introdução}

Tendo a perspectiva de educação como mediação cultural, em que a realidade é reproduzida a partir de chaves de leitura pedagógicas, propondo um espaço de discussão, leitura e decodificação de produções e linguagens midiáticas que estão onipresentes em nosso cotidiano cultural, o que despertou em nós o desejo de estudar este tema foi a relação entre o cotidiano e as nuances de uma sociedade próxima à nossa. Articulamos com autores da área de Educação e percebemos potencialidades de análise com este anime como objeto de pesquisa, estabelecendo hipóteses que nos impulsionam a ter um olhar mais atento nesta narrativa.

É relevante falar desse anime, pois, desde a finada TV Manchete (1983 - 1999), o gênero animação japonesa ganhou o gosto e uma legião de fãs brasileiros. Dessa forma, a emissora que ajudou a propagar essas obras, foi seguida dos principais canais de televisão, SBT(1981), Rede Record (1953), Bandeirantes (1967), Rede TV (1999) e Rede Globo (1965), que a transmitirem animações japonesas diversas. Infelizmente, no segundo semestre de 2015, o programa que apresentava desenhos animados nas manhãs na Rede Globo, a TV Globinho, exibe sua última transmissão, deixando o público jovem sem desenhos, sendo substituído pela atual programação Encontro com Fátima Bernardes (2012 -). Essa substituição gerou uma lacuna de 5 anos sem exibição do gênero em TV aberta, fazendo com que jovens mais aficionados pelos desenhos japoneses ficassem sem contato com animações nipônicas. Desse modo, apenas o canal SBT continuou a transmitir animações japonesas pelas manhãs, fazendo com que os fãs migrassem para plataformas de streaming tais como Funimation (1994) e Crunchyroll (2006), lançadas em 2020 e 2012 no Brasil, ou recorressem a outros meios não oficiais para assistirem animes. Com a vinda do canal Loading (2020), rompeu-se essa ausência de programas infanto juvenil com a exibição de desenhos animados, animes e programas voltados para um público nerd e geek ${ }^{1}$. Afinal, a Loading tem como proposta justamente buscar o jovem que já não se vê representado na TV, uma vez que as demais emissoras abertas olham pouco para esse público. Salvo uma ou outra aposta isolada, atrações como animes e games não têm espaço nos canais convencionais. Logo, o surgimento desse canal proporciona em sua programação o anime Boku no Hero Academy (My Hero Academia) que será trabalhado nas páginas a seguir, sendo uma possibilidade de todas as crianças terem contato com a obra.

Para uma melhor familiarização do leitor com este estudo, é preciso ter uma breve compreensão do objeto de pesquisa que será trabalhado. As histórias em quadrinhos (HQs) são

${ }^{1}$ Termo utilizado para designar pessoas atraídas pelas novas tecnologias, cultura pop relacionadas a quadrinhos, mangás, séries e filmes. 
um dos maiores e mais sérios ramos da indústria editorial japonesa, assim, o Japão é um dos países que tem forte hábito de leitura (SATO,2007). Esses quadrinhos são conhecidos como mangá, que tem por resultado da união dos ideogramas man (humor, algo que não é sério) e gá (imagem, desenho), sendo assim, toda e qualquer HQs, japonesa ou não, é chamado de mangá, pois essa palavra significa "quadrinhos". No momento em que algum mangá ganha grande destaque nas produções, é realizada a produção para a transmissão em redes de televisão e streaming, conhecidos como anime ou animê. Quando mencionamos anime ou animê, conforme sua pronúncia, ambas estão certas, estamos falando de desenhos animados criados e produzidos no Japão. Esse termo anime/animê -, no Japão, é empregado para designar qualquer animação ou desenho animado, em que a forma contraída é a que os japoneses usam escrevem animação em inglês (animation) (SATO, 2007) e nós, ocidentais, adotamos o termo anime (ou animê) para diferenciar dos demais desenhos televisionados no resto do mundo. Nesse contexto, o anime é considerado um dos ramos principais da indústria do entretenimento japonesa, disseminando um pouco da sua cultura por meio da cultura pop mundo afora.

A escolha desse anime/mangá como objeto de pesquisa partiu das relações que ele trás com cotidiano escolar, como questões de representatividade e a capacidade de empatia e de determinação do protagonista Izuku Midoriya, que nos permitiram correlacionar com autores que se acercam da área da Educação. Nesta perspectiva, o anime/mangá se constitui por fragmentos da realidade, refletidos nos enredos dos personagens, por esse motivo, apropriamos-nos da mesma de forma natural, relacionando e estabelecendo representações com a realidade. Permitindo que o anime fosse visto não somente como entretenimento, mas sim como um meio de comunicação e como ferramenta educacional que merece atenção por parte dos acadêmicos e educadores, pois proporcionam influências/relações pedagógicas, destacamos suas possibilidades como a aproximação do aluno, sua estrutura e demais fatores que demonstram a capacidade desse eixo da cultura pop.

Após essa breve explicação, a nossa proposta é mostrar as potencialidades desse anime, possíveis intervenções e as capacidades de resiliência do personagem principal, Izuku "Deku" Midoriya. Ao realizar a análise desse artefato cultural, percebemos as competências do anime como meio de interação com o indivíduo no desenvolvimento da capacidade crítica e reflexiva. Assim, esse artigo tem como justificativa mostrar o anime em um estudo voltado na esfera da questão social e com os seguintes objetivos: a) apresentar os principais personagens do anime; b) descrever o contexto social, escolar e familiar do personagem; e, por fim, c) identificar relações professoraluno. 


\section{Metodologia}

A pesquisa ocorreu de modo a ponderar como os autores estão considerando os estudos referentes à cultura pop na educação, ou seja, é uma pesquisa qualitativa. Segundo Gil (2008), essa modalidade de pesquisa permite definir práticas orientadoras que garantem a padrão do estudo em questão. Complementando, tais documentos foram analisados por meio da Técnica de Análise de Conteúdo, proposta por Bardin (2011). Técnica que é dividida em três etapas, a saber: pré-análise, etapa em que se realiza uma leitura flutuante do material; exploração do material, na qual são estabelecidas as categorias de classificação; e, por fim, essas categorias passam pelo processo de tratamento, inferência e interpretação dos resultados. A primeira etapa das três propostas pela autora no tratamento de dados indica a pré-análise como sendo a fase de organização do material, em que o pesquisador seleciona o material, documentos, no nosso caso os artigos e os livros que contribuem nessa temática de acordo com os objetivos da pesquisa. Nessa primeira etapa, Bardin (2011) propõe a leitura flutuante como estratégia de acercamento aos documentos de forma objetiva, a escolha dos documentos, definindo os critérios de inclusão e exclusão, e, finalmente, a preparação do material, a leitura de forma cuidadosa dos textos, procurando as informações que podem contribuir para a compreensão de forma mais efetiva do objeto em estudo no trabalho. A segunda etapa é a exploração minuciosa do material selecionado, ou seja, é o momento em que o pesquisador se debruça de forma intensa sobre o conteúdo, apropriando-se da temática, com o intuito de atingir os objetivos. Enfim, a terceira etapa da análise trata e apresenta os dados de forma a ganharem sentido e comunicarem a intenção do pesquisador na elaboração do estudo em questão.

\section{O enredo, conhecendo My Hero Academia}

Dado uma prévia ao leitor sobre o termo anime/animê, é apresentado o nosso objeto de pesquisa, o anime Boku no Hero (2004), também conhecido como My Hero Academia no ocidente sendo, lançado em 2006 pelo estúdio japonês Bones Inc. (1998), produzido atualmente. A premissa dessa história se inicia com o personagem principal Izuku Midoriya ou "Deku", um jovem que nasce sem individualidade (poder) em um mundo que é normal tê-los, mas, mesmo assim, sonha em se tornar um super-herói. Já no primeiro episódio do anime, nos é explicado que a primeira habilidade se manifestou com um bebê brilhante que surgiu de repente na China e, depois disso, pessoas com poderes começaram a aparecer pelo mundo todo até o ponto em que $80 \%$ da humanidade desencadearam habilidades e poderes, e $20 \%$ não. 
O nosso protagonista está dentro deste grupo de $20 \%$ da população, em que não tem nenhum tipo de individualidade, porém sempre buscou se esforçar para que pudesse ser aceito pelo Colégio U.A. (é uma das academias onde os alunos aprendem e treinam para se tornarem heróis, sendo o principal cenário em que a história ocorre, considerada como Ensino Médio) e proporcionar orgulho a sua mãe com alguma individualidade, o que se resume em um episódio em que ele vai ao médico e o profissional lhe informa ser uma criança normal, sem nenhum tipo de manifestação de individualidade (poder) em particular, gerando o sentimento de culpa na mãe, pois essa também não possuí habilidades heroicas, contudo, o personagem seguia acreditando nas possibilidades de se tornar um herói. $\mathrm{Na}$ mesma proporção que a sociedade se adaptava à nova realidade, em que, com os super poderes, veio o aumento no índice de criminalidade. Enquanto o país avançava lentamente com as drásticas reformas legais de proteção civil, pessoas corajosas começaram a realizar atos heroicos inspiradas em histórias em quadrinhos (HQs) ao defenderem a população dos indivíduos que utilizavam suas individualidades para o mal, conhecidos como vilões. Sendo assim, a sociedade aceitou os super-heróis como trabalho oficial, e eles eram pagos pelo governo conforme o seu desempenho contra o crime.

\section{Personagens principais}

Izuku Midoriya — também conhecido como Deku — nasceu sem nenhum poder em um mundo em que $80 \%$ das pessoas já nascem com as denominadas individualidades. Por esse motivo, foi alvo de piadas e desprezo de seus colegas de escola, sendo, inclusive, atormentado por Katsuki Bakugou, seu amigo de infância, que ria das aspirações de Deku de se tornar um herói um dia. Quando Midoriya arrisca sua vida, mesmo sem ter poderes, para salvar Katsuki de um vilão, o ídolo All Might decide que ele é digno de se tornar um herói, assim, passa para o menino o seu poder One For All - que é repassado por gerações e que acumula a energia de cada um dos usuários anteriores. Após ter passado por um pesado treino de 10 meses, Izuku recebe o poder e pode realizar seu sonho de trilhar o caminho para ser um herói, dessa forma, ele passa a controlar cada vez mais suas habilidades. Antes de obter o poder do All Might, quando não tinha individualidade, ele estudava os poderes de heróis profissionais e vilões, anotando tudo em cadernos para que usasse no futuro, o que vem a ser muito útil em batalhas futuras. Juntamente com seus amigos do Colégio U.A (Ochaco Uraraka e Ten'ya Iida), tem uma frase de efeito do herói número 1, All Might, que usa este lema ao liberar o seu poder: Vai Plus Ultra. O enunciado é utilizado antes dos personagens, como forma de demonstrarem determinação ao enfrentarem desafios ou uma batalha. 
Inko Midoriya, mãe do personagem principal, é uma personagem que não apresenta muita participação no anime, pois aparece nos primeiros episódios e em momentos de quando Midoriya era criança. No entanto, em suas aparições, sempre é considerada uma mãe incrível, a todo o momento apoiando e ajudando o seu filho. A mulher tem uma personalidade bem parecida com a de seu filho, buscando sempre assegurar a felicidade e o bem estar do menino, mesmo que não concorde com a situação.

Toshinori Yagi (All Might) é considerado o maior super-herói de sua época, porque é o herói da paz que traz um sorriso para a vida das pessoas com o jargão "Está tudo bem! Sabem por quê? Por que eu cheguei!" seguido de uma risada ao salvar as pessoas. Ele é o ídolo número um de Izuku Midoriya e Katsuki Bakugou. Sua fisionomia é de um herói super musculoso e alto, mas faz parte de sua individualidade quando ativada, quando não está, sua aparência fica irreconhecível, magro e cabeludo, ele também é o oitavo portador da individualidade One for All (em uma tradução literária Um por Todos) que lhe dá poderes surpreendentes, força, velocidade, invulnerabilidade, imenso vigor e um espírito indomável. Atualmente, Toshinori escolheu Midoriya para ser seu sucessor, passando a sua individualidade para o garoto após um intenso treinamento, e é professor no Colégio UA.

Katsuki Bakugou é o amigo de infância de Midoriya, que aparece desde o primeiro capítulo do anime, sempre demonstrando alguma implicância com o seu colega. É um dos personagens que desenvolveu uma personalidade agressiva e complexa carregada de um ar de superioridade, cometendo até mesmo bullying com Midoriya por ele não ter nenhum poder. No universo de $M y$ Hero Academia, Bakugou tem uma personalidade extremamente explosiva, mas não é um vilão, ele é um personagem inteligente, que se destaca impressionando e assustando a todos com a sua maneira brutal de lutar, todavia, essa personalidade pode o prejudicar no seu progresso no Colégio UA.

Shouta Aizawa é professor da U.A (responsável pela turma 1-A) e herói profissional Eraserhead (anula individualidades). Shouta é um homem muito severo e reservado, com grandes expectativas diante dos seus alunos. Muito racional, movido principalmente pela lógica, tem como principal premissa ensinar e desenvolver o conhecimento necessário para que os alunos sejam futuros heróis de excelência. Constantemente motiva o Midoriya, protagonista dessa trama, a ficar mais confiante, logo, eles têm aquela básica relação entre aluno e professor, com trocas de experiências, com o intuito de fortalecer e orientar o jovem a desenvolver suas potencialidades e crescer emocionalmente. Por vários momentos, presenciamos Aizawa chamar a atenção do estudante Midoriya por suas atitudes impulsivas, mas também admira e se surpreende com os feitos 
do nosso querido protagonista e por sua determinação e senso de justiça. Aizawa demonstra ser um grande educador ao cuidar dos alunos, impulsionando-os a desenvolver suas individualidades e questões emocionais.

Ochaco Uraraka, amiga e colega da turma 1-A do Colégio U.A, tem personalidade alegre e gentil, sempre está disposta a ajudar seus amigos, principalmente Ten'ya Iida e Izuku Midoriya. Extremamente inteligente, escolheu seguir o sonho de ser heroína para ajudar sua família em questões financeiras. Sua individualidade consiste em tirar a gravidade de objetos apenas por meio de um toque ou também flutuar, assim, de forma estratégica pode usá-los como armas, escudos, etc.

Ten'ya Iida, amigo e líder da turma 1-A do colégio UA, Ten'ya tem a personalidade de uma pessoa séria, educada e racional, qualidades essas que o levou ao posto atual dentro da turma 1-A. Determinado em ser disciplinado e portador de um grande senso de organização, mas humilde e leal, busca proteger seus colegas de classe, mesmo assim, é capaz de quebrar as regras para defender seus colegas.

A Liga dos Vilões é constituída por um grupo de jovens que pretendem abalar a sociedade enfraquecendo as referências sociais de poder e proteção, os heróis em específico All Might (o herói número um e símbolo da paz) e o colégio U.A, que representa o futuro da sociedade, com a formação de novos heróis.

\section{Contexto social, familiar e escolar}

Como citado anteriormente, o personagem vive em uma sociedade ficcional, porém, as adversidades na narrativa do anime se sobressaem com as que estão presentes em nossa sociedade como um todo, tais como: injustiça social, conflitos, ausência de políticas públicas na sociedade, conflitos em escolas, bullying e preconceitos. No primeiro episódio do anime, o personagem principal demonstra o seu entusiasmo diante a ação dos heróis combatendo o crime em uma grande avenida, nesse cenário, Midoriya puxa um caderno de anotações para observar os poderes do superherói que combateu recentemente o vilão, analisando os prós e contra das individualidades do mesmo. Essa atitude demonstra, segundo Piaget (1987), o grau de desenvolvimento do educando, isto é, o quanto ele está articulado a sua relação de atuação com o mundo.

Piaget considera que, ao longo do desenvolvimento do corpo e da aprendizagem, a criança vai construindo uma série de estruturas internas, progressivamente, de forma a conseguir lidar com objetos e situações ao longo de seu crescimento. Essas estruturas são classificadas em estágios e, assim, tem-se o estágio sensório-motor, o estágio de representação pré-operacional, o estágio das 
operações concretas e o estágio das operações formais ou hipotético-dedutivas. Em sua pesquisa, o autor identifica essas condições e as relaciona com os conteúdos de aprendizagem, estabelecendo uma conexão direta entre os estágios das estruturas internas e os estímulos pedagógicos sobre as quais elas operam.

Os valores sociais influenciam o protagonista na formação de sua identidade pelo fato de querer ser um herói mesmo sem possuir poderes, com o principal objetivo de fazer o bem. Em sua escola, ele, por não possuir nenhuma individualidade, sofre bullying de seu amigo de infância, Katsuki Bakugo, que diz que ele é um inútil e imprestável, que não tinha um dom e, por isso, deveria pular da laje da escola. Mesmo enfrentando esses abusos exercidos pelo seu colega, o jovem Midoriya não desiste do seu sonho em ser um herói, sendo assim, busca em grandes heróis presentes em seu contexto e em histórias em quadrinhos essas representações sociais,potencializando as virtudes intrínsecas em sua personalidade. Cabe salientar que o autor Weschenfelder (2011), quando cita a palavra virtude, define-a como a maneira com que cada qual pode influir, predominantemente ao modo da imitação, sobre a formação do gosto moral, da sensibilidade sócio-moral de crianças e adolescentes que lêem as HQs ou que assistem aos filmes sobre essas histórias, no nosso caso, o anime.

\footnotetext{
O ser humano aprende a agir corretamente ao ser repreendido por um mau comportamento e ao ser recompensado quando faz o bem. Se desejarmos instilar determinadas virtudes específicas, como a coragem, devemos testar a pessoa que receberá tal caráter. A coragem nasce da atitude de enfrentar o perigo. Para Aristóteles, a virtude não é apenas um conhecimento, mas um hábito voluntário, algo que resulta de um exercício persistente e consistente, que não se adquire através do ensino, pois sim pela prática. (Weschenfelder, 2011, p. 46)
}

Midoriya, ao adquirir seus poderes após um árduo treinamento com seu tutor All Might, para ser admitido no Colégio U.A, precisa realizar provas de admissão, ao passar nas provas admissionais, o jovem Midoriya se sentiu inserido ao contexto escolar, por ter individualidade. Dessa forma, construiu novas relações de amizades com Ochaco Uraraka e Ten'ya Iida, fortalecendo, assim, aspectos afetivos/emocionais em seu processo de ensino/aprendizagem, tendo, em consequência, apoio em situações de adversidade como o bullying que se define " [...] como um conjunto de atitudes agressivas intencionais que se repetem com o intuito de intimidar e/ou agredir, causando dor e angústia à vítima, em uma relação de desequilíbrio de poder entre as partes envolvidas." (OLIVEIRA et al, apud OLIVEIRA-MENEGOTTO; PASINI; LAVANDOWSKI, 2018, p. 2).

Para contextualizar, nessa trama, a individualidade determina sua profissão ou contribuição com a sociedade. Pessoas com determinadas "individualidades" podem trabalhar como heróis em 
áreas que combinem com suas personalidades, aqueles que não têm uma individualidade desenvolvem os serviços comuns dentro de uma sociedade, tais como motoristas, bombeiros, policiais, jornalistas e demais trabalhos. Já aqueles que não possuem poderes ficam sem espaço, enquadrando-se no grupo de vulnerabilidade social,apresentados para nós como os "bandidos" que saqueiam lojas e assaltam bancos enquanto as demais pessoas têm seus trabalhos comuns, somando à sociedade. Uma observação a ser feita é que o autor do mangá e anime, Kohei Horikoshi (1986 - ), não exemplificou especificamente uma hierarquia social, cabendo ao leitor ou espectador da obra interpretar essa visão de hierarquização ou divisão social. Porém, para preencher essas lacunas deixadas pelo o autor, trazemos o estudo de Chartier (2002) que, ao falar sobre as novas formas de práticas e representações no estudo da História Cultural, afirma que todas as formas culturais em que é discernida por um historiador ou pesquisador reconhecem a cultura do povo e suas nuances, aqui relacionadas a não exemplificação que o criador da obra deixa em segundo plano, abrindo as possibilidades de interpretações do pesquisador sobre a obra, no caso, o contexto social e demais vertentes. Sendo assim, é uma difícil tarefa desembaraçar essas origens bastante diversas, mas um alerta nos é dado pelo autor Chartier (2002): ler, olhar, ou escutar são, efetivamente, uma série de atitudes intelectuais que permitem, na verdade, a reapropriação. Por isso, o objeto ou fonte a ser estudado é uma representação de seu tempo, cabendo ao historiador/pesquisador filtrar e delimitar com os métodos corretos e bem fundamentados, buscando autores que publicaram temas semelhantes sobre a fonte de pesquisa, sendo livros, artigos, dissertações e teses para a elaboração da pesquisa estar bem fundamentada.

A sociedade determina valores e modelos que se refletem nos aspectos familiares. Essas representações estão presentes no anime e nos anseios em que o personagem principal demonstra ao querer se tornar um herói, o que é muito explícito nas falas, pensamentos e atitudes feitas pelo Midoriya, pois essa sociedade retratada no anime tem como ideologia e base o herói como modelo de virtudes e de representação de segurança, aquele capaz de ajudar e proteger o povo. Então, de certa forma, os padrões pré-estabelecidos nesta sociedade influenciam na formação da identidade desse sujeito, conforme a autora citada abaixo, colabora:

Enfim, a criança nasce dentro de uma sociedade com seus valores e padrões apropriados e através da interação com outros seres humanos, especialmente os mais experientes, ela apreende elementos do mundo social - a fim de funcionar dentro dele -, que auxiliam numa definição desse mundo e servem de modelo para as suas atitudes e comportamento, podendo ser de maior ou menor importância, mas que ajudam a criança a determinar sua própria personalidade. (DE SOUSA, 2008, p. 2). 
Partindo dessa premissa, relacionamos que esses valores determinam os caminhos que sustentam os sonhos de Izuku Midoriya em ser um herói, e uma peça primordial para a chegada desse objetivo é a formação intelectual oferecida pelo Colégio U.A e o apoio familiar de sua mãe, Inko Midoriya. No anime, é apresentada a importância que o papel da escola exerce sobre a formação do ser social das crianças frente a sociedade que irá recebê-las, por meio da fala de uma professora dos anos iniciais, em que diz que os primeiros anos do primário são essenciais para formar a personalidade, pois as individualidades influenciam significamente no desenvolvimento dos alunos. Nesse contexto,a instituição de ensino oferece aconselhamentos e suporte emocional para que os alunos mantenham uma mente saudável, mas não é um método perfeito, e as crianças necessitam de apoio familiar para o desenvolvimento dessas capacidades, então, escola e família se constituem alicerces na formação do indivíduo.

Diante os estudos de Perrenoud (2001), a escola desempenha um papel muito importante no desenvolvimento da criança e, principalmente, no núcleo familiar e em como essa família se modifica ao longo do tempo diante dos estudos da sua prole. Conforme o avanço da criança na vida escolar, a família vai se organizando em função dos horários da escola, das exigências da instituição e outras funções que é pertinente aos pais no período em que seus filhos estão no ambiente escolar. Ainda, é necessário ressaltar que nem todas as famílias vivem da mesma forma a escolaridade dos filhos, experiência pode ser feliz para algumas e para outras um verdadeiro calvário, uma fonte de conflitos e de humilhações (PERRENOUD, 2001). Por conseguinte, Midoriya encaixa-se no primeiro grupo, é filho de mãe solo, criado com base em valores essenciais para o bem viver: responsabilidade, honestidade, respeito e humildade. Ao que referimos sobre essa importância da presença da família na vida educacional da criança, há uma passagem de um artigo que corrobora com nosso ponto de vista:

\begin{abstract}
O ambiente familiar é o ponto primário da relação direta com seus membros, onde a criança cresce, atua, desenvolve e expõe seus sentimentos, experimenta as primeiras recompensas e punições, a primeira imagem de si mesma e seus primeiros modelos de comportamentos - que vão se inscrevendo no interior dela e configurando seu mundo interior. Isto contribui para a formação de uma "base de personalidade", além de funcionar como fator determinante no desenvolvimento da consciência, sujeita a influências subseqüentes. (DE SOUSA, 2008. p. 2)
\end{abstract}

Logo, observamos que o núcleo familiar é o primeiro meio de interação social que a criança obtém, tornando esse núcleo o primeiro e o mais importante agente socializador, criando preceitos de socializações em que seu aprendizado primário irá refletir na sua vida escolar. Sendo assim, o desenvolvimento da criança não poderá ser obtido apenas individualmente ou seccional, para obter uma excelência no aprendizado, será necessária uma rede de vínculos entre família e escola. 
Observamos nesse animê que a escola é representada como pilar de uma sociedade, sendo princípio de poder, proteção e o futuro da nação, pois essa capacita jovens para serem heróis. Em convergência com essas afirmações que o objeto de pesquisa nos trás, no caso do Brasil, temos a Lei de Diretrizes e Bases da Educação Nacional (1996) que busca estabelecer processos que abrangem âmbito familiar, trabalho e movimentos sociais vinculados à prática social. Em um fragmento do anime, presenciamos o diretor da Escola U.A em um discurso de recepção aos alunos, enfatizando a importância dos educandos para a sociedade, que eles são o futuro e que a escola tem como base educar e proteger, proporcionando uma formação integral. Portanto, fica delegada à escola o papel de formação de novas gerações que tenham a oportunidade de contato com uma pluralidade de culturas socialmente valorizadas na formação do cidadão social.

No anime, são apresentados dois âmbitos escolares. O primeiro são as escolas tradicionais, nas quais o ensino está focado na educação bancária que, segundo Freire (1996), visa a transmissão de conteúdo, como se o educando fosse um banco. Nessa escola tradicional, lugar onde o protagonista Izuku Midoriya realiza o Ensino Fundamental,, o professor da turma, que não é identificado no anime, mas que traz a persona do professor tradicional como citado acima, nos apresenta a fala que, apesar do personagem ser uma dos alunos que detém uma boa nota, se eles não estudar não irá passar nas academias que almeja. O protagonista era considerado minoria, subestimado por colegas e professores por sua falta de poderes, sendo excluído e sofrendo bullying. Mesmo assim, o personagem nos emociona com sua capacidade de superar tais dificuldades de forma surpreendente, demonstrando-se um adolescente sonhador e determinado, com grande capacidade de empatia.

A segunda modalidade de ensino é representada na trama como o Colégio U. A, considerado Ensino Médio como citado acima, que tem como base a Educação Libertadora ou Problematizadora Freire (1987), que consiste em estimular o educando a participar ativamente de seu processo de aprendizagem, tendo como princípios o diálogo e os questionamentos gerados. Dessa forma, o Colégio U.A é uma das academias onde os alunos aprendem e treinam para se tornarem heróis, aprimorando suas habilidades e internalizando conhecimentos, destacando-se como modelo de ensino, considerada a melhor do Japão. Nessa escola, os estudantes são divididos em Departamentos e Classes específicas — A,B,C,D etc — de acordo com suas “individualidades". Nela, os alunos são orientados a controlarem seus poderes e usá-los com responsabilidade. Nesse âmbito escolar, Izuku Midoriya se destaca pela sua capacidade de adaptação e resolução de problemas a partir de seu conhecimento prévio e de seu diário de anotações. 
As duas abordagens destacadas - a Educação Bancária e a Educação Libertadora ou Problematizadora Freire (1987)—, constituem-se presentes no anime, fazendo-nos refletir diante a aplicabilidade dessas metodologias e suas consequências no processo de ensino/aprendizagem dos educandos. Como professores, percebemos a relação existente entre essa ficção e a nossa realidade: o aluno, inúmeras vezes, não consegue prestar atenção em aula por diversos motivos, cabendo ao professor modificar suas metodologia e trabalhar novas formas de educar para potencializar e aguçar o conhecimento do aluno. Sendo assim, destacamos a principal funcionalidade da escola: ser um lugar de trabalho, de ensino/aprendizagem, um local em que o convívio permita estar continuamente se superando, pois a escola é o espaço destinado para fazer o pensar. Diante disso, a escola deve ser representada como instância da coletividade. Freire (2007, p. 30) enuncia que "não é a educação que forma a sociedade de uma determinada maneira, senão que esta, tendo-se formado a si mesma de uma certa forma, estabelece a educação que está de acordo com os valores que guiam essa sociedade". Um aspecto bem presente no anime Boku no Hero vai ao encontro das pretensões dos valores da escola de Freire (1996), em que a escola desempenha um papel importantíssimo na estruturação social e educativa dentro de uma sociedade, com características de uma escola forte, autêntica, com alunos críticos e reflexivos a seu tempo. Com a premissa de tornar os educandos sujeitos críticos e reflexivos, que visam a transformação da sociedade e o desenvolvimento do educando, entendemos que a escola se constitui de forma ampla, segundo Luckesi (2010), a construção do indivíduo atende questões cognitivas, afetivas, psicomotoras e o estilo de vida. À vista disso, a escola tem grande influência nessa formação, sendo assim, deve ser um lugar onde cada aluno encontre a possibilidade de se instrumentalizar para a realização de interação social, legitimando o respeito próprio, pelo outro, pelos valores e regras morais.

\footnotetext{
Cada sujeito criança, jovem ou adulto se educa no processo social como um todo; na trama das relações familiares, grupais, políticas... A educação é o meio pelo qual a sociedade se reproduz e se renova cultural e espiritualmente, com conseqüências materiais. A sociedade necessita reproduzir-se para manter o estágio de desenvolvimento a que chegou, mas necessita também renovar-se para atender às necessidades e aos desafios emergentes. A educação, nas suas diversas possibilidades, serve à reprodução mas também à renovação da sociedade. Assim sendo, desenvolvimento do educando significa a formação de suas convicções afetivas, sociais, políticas; significa o desenvolvimento de suas capacidades cognoscitivas e habilidades psicomotoras; enfim, sua capacidade e seu modo de viver. (LUCKESI, 2010, p. 126).
}

Os ambientes escolares presenciados no anime exibem uma familiaridade com o sistema de ensino ocidental que se articulam em práticas tradicionais e libertadoras Freire (1987), mostrando-se trivial para a formação do indivíduo e para sua inserção ao contexto social, 
reforçando valores e agregando ao desenvolvimento da identidade dos alunos. Diante disso, salientamos a real funcionalidade da escola, uma vez que deve ser um lugar onde cada aluno encontre a possibilidade de se instrumentalizar para a realização de interação social, legitimando o respeito próprio, pelo outro, pelos valores e regras morais. É por meio do trabalho na dimensão afetiva que a escola conseguirá tocar a sensibilidade das pessoas.

Para Delors (2001), um dos maiores desafios da educação é o aprender a viver junto, aprender a conviver com os outros. "A história humana sempre foi conflituosa, mas há elementos novos que acentuam o perigo e, especialmente, o extraordinário potencial de autodestruição criado pela humanidade no decorrer do século XX (DELORS, 2001, p. 96)”, nesse sentido, o grande desafio da educação que conhecemos e do Colégio U.A descrito no anime Boku no Hero (2004) é ajudar o aluno a refletir sobre o mundo no qual está inserido, priorizando o ser e não o ter, levandoo a ser crítico e construir uma sociedade melhor, para isso, a equipe docente deve dar subsídios para reflexão, um olhar que se diferencia e que prioriza o ser humano e não o preconceito que a sociedade já estabeleceu, pois, ela é extremamente seletiva e classifica em classes dentro dos diferentes conceitos. Essas demandas estão bem presentes na trama do anime, por esse motivo, dedicamos um tópico para relação professor-aluno. Estabelecemos a associação entre contexto social, familiar e escolar é fundamental para a formação do indivíduo, e que tais áreas devem trabalhar em conjunto. Sendo assim, o ambiente proporciona valores e padrões de interação com demais grupos. Essas indagações estão evidentes no enredo no anime, fazendo-nos refletir diante as proximidades entre ficção e realidade, revelando-se um objeto de pesquisa de grande potencial.

\section{Relação professor-aluno: vai plus ultra!!!}

Diante o que foi exposto anteriormente, ressaltamos outra peça fundamental da escola: o educador. Nesse objeto de estudo, presenciamos a importância dos professores na formação de Midoriya, por isso, faremos uma breve apresentação desse contexto, tendo como ponto de reflexão, atualmente, o grande desafio da educação ser ajudar o aluno a refletir sobre o mundo no qual está inserido, Paulo Freire (1996), priorizando o ser e não o ter, levando-o a ser crítico e construir uma sociedade melhor. Para alcançar esse objetivo, o educador deve dar subsídios para reflexão, um olhar que se diferencia e que prioriza o ser humano e não o preconceito que a sociedade já estabeleceu, pois ela é extremamente seletiva e classifica em classes dentro dos diferentes conceitos.

Nessa trama, destacamos dois educadores, Aizawa Shouta e Toshinori Yagi (All Might), do colégio U.A, que auxiliam os jovens da instituição a desenvolverem suas habilidades, controlarem seus poderes e criarem estratégias de combate, para que eles saibam se adaptar a qualquer situação, 
ou seja, aspectos essenciais para esses alunos se tornarem heróis. Nessa perspetiva, os professores citados se apresentam como mediadores da turma 1-A, contribuem para que os educandos tenham claras as suas responsabilidades e que tenham discernimento ao resolverem situações de conflito, tendo uma postura reflexiva diante suas decisões de heróis profissionais. Dessa maneira, criam uma conduta integrada de interação professor/aluno, para que a educação não seja bancária e para que haja a troca de vivências e experiências, construindo um espaço agradável e afetivo de desenvolvimento do ensino-aprendizagem, no caso do anime em questão, o desenvolvimento e aprimoramento de individualidades (poderes). Partindo desse contexto, destacamos a função do educador no processo de construção do conhecimento.

\footnotetext{
Nessa conjuntura, o professor está presente como mediador, facilitador e catalisador do processo de aprendizagem. Sua presença se faz absolutamente indispensável como elemento organizador do contexto de aprendizagem, com vistas a facilitar o processo de construção das representações pelo aluno. Fica, então, claro que o professor não é transmissor de conhecimento, e sim aquele que prepara as melhores condições para que sua construção se efetue. (MORETTO, 2010, p.44).
}

Elemento essencial na efetivação da aprendizagem é uma autoestima positiva, pois todo indivíduo precisa sentir-se capaz de pensar e agir e ver-se como merecedor de suas aprendizagens no contexto. Este fato de incentivar o aluno a acreditar em suas habilidades,também se faz presente no anime Boku no Hero Academia (My Hero Academia), fortalecendo a relação professor-aluno entre Izuku Midoriya, Aizawa Shouta e All Might. Esses educadores impulsionam o aluno a encontrar o seu potencial de aprendizagem, fazendo com que desenvolva estratégias e amplie seu pensamento crítico e reflexivo na tomada de decisões, orientando esse aluno a ter dedicação para ir mais longe, alcançar o $100 \%$ de seu potencial.

O diálogo estabelecido entre professor e aluno é fator extremamente importante no processo de aprendizagem, visto que forma elos afetivos que despertam o interesse e a motivação, levando os alunos a executarem suas tarefas com boa vontade e determinação, pois "interagir indica um processo de construção de representações em que o aluno faz experiências sucessivas com um objeto de conhecimento socialmente construído, para construir suas próprias representações." Moretto (2010, p.44). Nessa perspectiva, é possível relacionar tal informação às vivências do animê, em que os educadores sustentam o processo de aquisição de aprendizagens a partir das experiências, propiciando ao aluno estabelecer aprendizagens significativas.

Para afirmação dessa reflexão, convergimos com os pensamentos de Vygotsky (2007) de que, em suas formulações teóricas, a cultura se faz subjetiva no aprendente, sendo possível somente com a intermediação do adulto, não negando a condição do sujeito como construtor ativo de sua 
aprendizagem, pois, para o autor, a maioria do conhecimento não pode ser aprendida pelo aluno sem ajuda de um docente que lhe ofereça a oportunidade de lidar com signos, procedimentos e valores, que são da ordem social e que transcendem e preexistem a ambos.

Vygotsky (2003) concebe a função do professor como sendo de extrema importância, pois seria o docente que, a partir da organização dos espaços, do currículo, do conteúdo e da sala, proporciona as experiências adequadas para que o desenvolvimento do conhecimento do aluno ocorra, em uma relação dialética entre o conhecimento prévio adquirido do ensino escolar e as novas situações de aprendizagem propostas na escola. Segundo Costa (2019), a concepção do papel docente habilita e transcende a interpretação do educador ser o único detentor do conhecimento. Dessa forma, por meio das situações de aprendizagem e da organização do ambiente social, é possível estimular, orientar e instigar o educando no processo de aprendizagem.

Diante das implicações de Vygotsky e de Piaget, percebemos que o papel do professor deve superar a visão tradicional - educação bancária - e os modelos em que ele detém o conhecimento e apenas se encarrega de transmiti-lo aos seus alunos. Esse ponto de vista exclui os fundamentos norteadores do desenvolvimento da aprendizagem que partem do princípio do conhecimento prévio e vivências do educando, explorando suas experiências, tornando-as fonte de aprendizado e meio de comunicação entre professor e aluno, estabelecendo uma relação que potencializa a efetivação da prática. Com tudo, buscamos ressaltar que a didática centralizada na aprendizagem significativa e a disposição dos ambientes e dos objetos podem contribuir para a interatividade produtiva das crianças no ambiente escolar, ressignificando o aprendizado e potencializando as capacidades cognitivas dos alunos, destacamos os estudos de Vygotsky e de Piaget e demais estudiosos na atividade docente, no contexto do anime aqui apresentado.

\section{Algumas reflexões a serem consideradas}

Trazer para o espaço educacional esse tipo de entretenimento da cultura, pop, permitiunos que o anime fosse visto não somente como entretenimento, mas também como um meio de possibilidades, comunicação e ferramenta educacional que merece uma atenção do olhar acadêmico para ser inserido na Educação, pois conversar com nossos alunos não é apenas planejamentos e metodologias, é adentrar no universo cultural do aluno.

Os objetivos foram alcançados mediante a visualização da animação a ser estudada, realizando anotações e apontamentos no decorrer de cada episódio e correlacionando previamente com autores da área da Educação e de nossas vivências como educadores. Para que não caíssemos no estigma de pesquisar por pesquisar, buscamos, na elaboração desta pesquisa, metodologias de 
pesquisa baseando-se nos autores Bardin (2011) e Gil (2008), no que tange a análise de conteúdo e permite um definir práticas orientadoras que garantisse aos pesquisadores um padrão de estudo satisfatório frente a nossas expectativas diante o potencial pedagógico do anime.

Com o presente embasamento metodológico, as possibilidades tornam viáveis o estudo desse anime. Em um dos primeiros objetivos, a apresentação dos personagens ao leitor possibilita, de início, o contato com suas personalidades e o impacto que irá surgir no decorrer da leitura proposta, uma vez que são personagens cativantes e repletos de nuances extremamente importantes para o desenrolar da narrativa, cheios de moralidades pertinentes ao que se refere nos estudos aqui propostos: escola, sociedade, família, aluno e professores.

Descrevemos o contexto social, familiar e escolar do personagem de acordo com as reflexões de Perrenoud (2001), destacando como essa tríade se torna essencial para o desenvolvimento e constituição da personalidade do ser humano e como os valores presentes nessa sociedade ficcional impulsionam os indivíduos (Chartier, 2002). Também apontamos os ganhos pedagógicos ao relacionarmos o contexto social, familiar e escolar, em que, primeiramente, buscamos trabalhar que, no aspecto social, certos valores influenciam a formação de identidade do aluno, mesmo que ele sofra adversidades, se conduzidas corretamente, é possível que o aluno possa desempenhar uma ascensão em sua jornada pessoal, estudantil e futuramente profissional. No âmbito familiar, destacamos a importância da mãe solo do personagem que, em suas aparições, desenvolveu uma estrutura de ambiente e sentimentos intrínsecos à maternidade na formação do seu filho, sendo o núcleo primário de interação social (De Sousa, 2008). Quanto à escola, é destacado a importância da sua construção na elaboração e desenvolvimento do aluno e o retorno que terá para a grande sociedade como resultado.

Identificamos a relação professor-aluno (Moretto, 2001) presentes na saga e que ela se aproxima da realidade educacional, então, o papel do educador se torna essencial para a formação integral do indivíduo, sendo capaz de orientar o educando no desenvolvimento de suas individualidades (poderes), lapidando-o para ser apto a ler o mundo, tornando-se um ser social, responsável por suas atitudes, adaptável às adversidades e conflitos existentes no caminho escolhido, assim, tornando-se um herói. Também foi possível corroborar nosso posicionamento diante os métodos empregados por educadores e escola no enredo de Boku no Hero Academia (My Hero Academia), como tais métodos e concepções de ensino, como a Educação Libertadora (Freire, 1996), podem propiciar o educando a ser protagonista de sua aprendizagem e como os personagens Aizawa Shouta e Toshinori Yagi (All Might), professores/mediadores da turma 1-A, contribuem a partir de sua didática, propiciando aos alunos um espaço agradável e aberto para a 
troca de experiências, estratégias para a elevação da autoestima, e desenvolvendo parâmetros para ampliar pensamento crítico e reflexivo, aspectos essenciais para a efetivação da relação professoraluno (Vygostky, 2007).

Para pesquisas futuras, destacamos as capacidades de escrita diante ao anime, tais como: a capacidade de resiliência do protagonista Izuku "Deku" Midoriya e suas virtudes que o fizeram herói (Weschenfelder, 2011); a simbologia existente por trás do herói número um All Might como mito, constituindo-se um pilar da sociedade; e futuras intervenções educacionais. Dessa forma, a preferência por esse anime/mangá como objeto de pesquisa, com base em nossas relações profissionais, e por temáticas que acercam a representatividade e a capacidade de empatia e determinação do protagonista Izuku Midoriya, seu contexto social, familiar e educacional, nos permitiram correlacionar com autores da área da Educação.

O anime/mangá se constitui por fragmentos da realidade refletidos nos enredos dos personagens, por esse motivo, apropriamos-nos da mesma de forma natural, relacionando e estabelecendo relações tangíveis. Reforçamos o potencial do anime, demonstrando que esse artefato cultural não deve ser visto somente como entretenimento, mas sim como um meio de comunicação e como ferramenta educacional e objeto de pesquisa, que merece atenção por parte dos pesquisadores do âmbito educacional.

\section{Referências}

ACADEMIA. My Hero. Direção: Kenji Nagasaki. Produção: TOHO, Shueisha, Dentsu, Movic, MBS (1 ${ }^{a}$ temp.) YTV e Sony Music Entertainment (5ª temp.)r. Local: Japão. Mídia: Funimation (VOD) 2016, Loading (TV), 2020.

BARDIN, Laurence. Análise de conteúdo. São Paulo: Edições 70, 2011, 229 p.

BRASIL. Lei no 9.394, de 20 de dezembro de 1996. Estabelece as diretriz̧es e bases da educaşão nacional. Diário Oficial da União, Brasília, 23 de dezembro de 1996. Disponível em: http://www.planalto.gov.br/ccivil_03/leis/L9394.htm. Acesso em: 23 mar. 2021.

BUENO, José Geraldo Silveira. Função social da escola e organização do trabalho pedagógico. Educ. rev., Curitiba, n. 17, p. 101-110, June 2001. Disponível em: https://revistas.ufpr.br/educar/article/view/2070. Acesso em: 25 fev. 2021.

COSTA, Laís Renó Stábile. Et al. O papel do professor na aprendizagem da criança: uma discussão a partir das compreensões de Vygotsky e Piaget. Revista Científica Multidisciplinar Núcleo do Conhecimento. Ano 04, Ed. 01, Vol. 07, pp. 18-26 Janeiro de 2019. ISSN: 2448-0959

CHARTIER, Roger. A história cultural: entre práticas e representações. 2. ed. Lisboa: DIFEL, 2002. 244 p. (Memória e sociedade). 
DE SOUSA, A. P. A importância da parceria entre família e escola no desenvolvimento educacional. Revista Iberoamericana de Educación, v. 44, n. 7, p. 1-8, 10 ene. 2008

DELORS, J. Educação um tesouro a descobrir. Relatório para a Unesco da Comissão Internacional sobre a Educação para o Século XXI. 6. ed. Tradução José Carlos Eufrázio. São Paulo: Cortez, 2001.

FREIRE, Paulo. Pedagogia do oprimido. $17^{\mathrm{a}}$ ed. Rio de Janeiro: Paz e Terra, 1987

FREIRE, Paulo. Pedagogia da autonomia. Saberes necessários à prática educativa. 19. ed. São Paulo: Paz e Terra, 1996.

FREIRE, Paulo. Educação e mudança. 30ª ed.; Rio de Janeiro: Paz e Terra, 2007.

GIL, Antonio Carlos. Métodos e técnicas de pesquisa social. 6. ed. São Paulo : Atlas, 2008. p.200 ISBN 978-85-224-5142-5

HORIKOSHI, Kohei. My Hero Academia. 2016. São Paulo: JBC, 2016, 200 p. v. $1^{\circ}$

LUCKESI, Cipriano Carlos. Avaliação da aprendizagem escolar. 21. ed. São Paulo: Cortez, 2010. 180 p. ISBN 9788524905506.

MORETTO, Vasco Pedro. Prova: um momento privilegiado de estudo, não um acerto de contas. 9. ed. Rio de Janeiro: Lamparina, 2010. 186 p. ISBN 9788598271699.

OLIVEIRA, Beatriz Lima De et al.. Uma discussão acerca do bullying na institução escolar: uma abordagem psicopedagógica. Anais V CONEDU... Campina Grande: Realize Editora, 2018. Disponível em: <https://editorarealize.com.br/artigo/visualizar/49217>. Acesso em: 04/03/2021

PERRENOUD, Philippe. (2001a). Entre a Família e a Escola, a criança mensageira e mensagem. O Go-between. Em C. Montandon \& P. Perrenoud (Ed.), Entre Pais e Professores, um diálogo impossivel? Para uma Análise sociológica das interaccões Entre a Familia e a Escola (C. G. da Silva Traduções) (pp. 27-54). Oeiras: Celta.

PIAGET, Jean. (1987): O nascimento da inteligência. Rio de Janeiro: Ed. Guanabara, 2019.

SATO, Cristiane A. JAPOP: o poder da cultura pop japonesa. São Paulo: NSP, 2007.

VIGOTSKY, Lev Semenovich, 1896-1934. A formação social da mente: o desenvolvimento dos processos psicológicos superiores/ L.S. Vigotsky; organizadores Michel Cole... [et al.]; tradução: José Cipolla Neto, Luís Silveira Menna Barreto, Solange Castro Afeche. $7^{a}$. Ed. - São Paulo: Martins fontes, 2007. (Psicologia e pedagogia).

VYGOTSKY, L. S. A formação social da mente: O desenvolvimento dos processos psicológicos superiores. Ed. São Paulo: Martins Fontes, 1998

VYGOTSKY, Liev Semionovich. Psicologia Pedagógica. ARTMED, Porto Alegre: 2003. 
WESCHENFELDER, Gelson Vanderlei. Aspectos educativos das histórias em quadrinhos de super-heróis e sua importância na formação moral, na perspectiva da ética. 2011. Dissertação (Mestrado em Educação) Centro Universitário La Salle, Canoas, 2011. 